\title{
RDF/SRF EVOLUTION IN THE MSW SECTOR: COEXISTENCE OF BMT AND SELECTIVE COLLECTION
}

\author{
E.C. RADA \& M. RAGAZZI \\ Department of Civil and Environmental Engineering, University of Trento, Italy.
}

\begin{abstract}
Mechanical biological treatments (MBTs) are extensively used for managing municipal solid waste (MSW). There are four different methods: fertilizer or compost-like output production, biogas/energy production, wastederived fuel production and disposal in landfills. One issue is the varying characteristics of the waste fed over the lifetime of the plant. This problem is only partially related to the composition dynamics of the generated MSW. Indeed, the main source of input fluctuation of the plant is a result of the implementation of selective collection (SC) strategies, which modify the composition of residual MSW (RMSW). Often the SC strategies are not developed in harmony with the presence or planning of treatment plants, which can consequently suffer from significant variations. A lack of optimization in MSW management strategies and the implementation of new more stringent regulations applied to the final solid products from MBTs could result in a higher tariff for the users. This paper analyses these two problems in terms of two SC scenarios. The consequent effects on the composition of RMSW and on the performance of bio-drying (one of the MBTs options) are discussed. The effect of different SC strategies of MSW is analysed also in terms of RMSW suitability to be converted into refuse derived fuel/solid recovered fuel with simplified treatments. The role of respirometry is also discussed. Keywords: Biological mechanical treatment, municipal solid waste, refuse derived fuel, respirometry, selective collection, solid recovery fuel.
\end{abstract}

\section{INTRODUCTION}

The quantity of municipal solid waste (MSW) has increased strongly in the last decade and continues to do so worldwide. European Union (EU) policy on waste management recommends the recycling of material, energy recovery and waste treatment before landfilling. The Landfill Directive (1999/31/CE) in Europe led to significant restrictions in the landfill of biodegradable material (Respiration Activity after four days below $10 \mathrm{mgO}_{2} \mathrm{~g}^{-1}$ Ts or a Dynamic Respiration Index below $1000 \mathrm{mgO}_{2} \mathrm{~kg} \mathrm{vs}^{-1} \mathrm{~h}^{-1}$ ) and also put a limit on the lower heating value (LHV) of the landfilled material $\left(<13,000 \mathrm{~kJ} \mathrm{~kg}^{-1}\right)$ [1]. All EU member states must reduce the amount of biodegradable municipal waste sent to landfills based on the quantity landfilled in 1995, with $35 \%$ by 2013 and $50 \%$ by 2020 . In addition, states must introduce source-separation strategies. Sorting plants can be adopted as an alternative strategy for diverting the biodegradable fraction of MSW from landfills.

The viability of mechanical biological treatments (MBTs) is thus widely discussed in terms of MSW to comply with these EU directives.

At present, there are four different MBT options: fertilizer or compost-like output (CLO) production, biogas/energy production, RDF/SRF production and disposal in landfills [2-5]. Although MBTs are based on biological processes, generally one of the final products is used in combustion plants to obtain energy, taking into account EU regulations both for material recovery and energy (2001/77/EC).

The MBT concept was originally developed in the 1980s to divide the waste stream into a wet fine fraction and a dry coarse fraction. Later, with the introduction of the selective collection (SC) of the dry recyclable fraction and the development of the waste-to-energy sector, MBT was also used in treating the entire waste stream to produce fuel.

MBT plants have been proposed for new EU members, before landfilling, prior to the construction of combustion plants [6]. One advantage of bio-drying is that solid recovered fuel (SRF) can be produced, which can be quickly used in existing co-combustion plants, thus significantly reducing 
the landfill volume [7]. Bio-drying is a short-term process of aerobic bioconversion and is generally applied to MSW as is, or to residual MSW (RMSW) of SC. The aim is to exploit exothermic reactions to evaporate most of the moisture in the waste with the lowest conversion of organic carbon. Bio-dried material is the product obtained after bio-drying and which can be used to obtain a good SRF after an inert separation [8]. The alternative aerobic option adopted as MBT, based on an initial screening of the RMSW, is often characterized by a larger stream of materials to be landfilled [9]. In this case, SFR is generated through over-sieving.

The initial cycle of RDF was closed by the early 1990s due to low-quality fuel and/or absence of quality checks [10]. Today, the evolution of the regulation of RDF/SRF aims to guarantee the quality of the product, which is a key for its marketability [11]. Recent studies have thus set out to clarify the influence of the composition of waste streams and processing on SRF quality [11, 12]. Specific interest concerns the RDF heavy metal content due to the potential health implications [13, 14]. The chlorine content has also been focused on and its consequences on process management, corrosion and carcinogenic compound formation [12].

The market potential of SRF has been estimated by the European Recovered Fuel Organization [15] as 27-37 million tonnes per year. Combined heat and power plants could cover just over half of the potential use of SRF. Roughly, a third of the potential could be covered by power plants. The remainder could be used by cement kilns. The present production of SRF in Europe is around 16.5 million tonnes [16].

This paper analyses the consequences of the variations in SC efficiency on an existing or planned $\mathrm{MBT}$, and also the implementation of the new regulations applied to the final solid products from MBTs [17]. In fact, the core of MBT is the biological process; thus, there must be putrescible materials in the stream. High efficiencies of SC (higher than 50\%) can be obtained only by separating the sources of food waste [18]. As a consequence, the food waste remaining in the RMSW can decrease even below 10\%, which, thus, strongly impacts on the management of MBTs [19].

\section{RDF AND SRF CHARACTERIZATION AND EVOLUTION}

In the EU, the first definition of RDF was introduced by the technical norms UNI 9903:1-14: 'RDF is fuel derived from municipal solid waste through treatments aimed at the elimination of substances hazardous for combustion and to guarantee an adequate lower heating value (LHV), and to comply with the technical norms for its characterization'. These norms give all the characteristics, definitions, sampling methods, parameters of interest and analytical methods for RDF and for the refuse derived fuel of high quality (RDF_Q). RDF and RDF_Q were the fuels obtained from non-hazardous MSW and special waste (limited to a contribution of a maximum of 50\%) through treatment aimed at obtaining an adequate LHV for its use. RDF and RDF_Q were also classified as special waste and only RDF_Q was considered as a renewable source.

The technical specifications for RDF and RDF_Q are presented in Table 1.

Although the first norm on SRF was issued in 2006, in some European countries, the national regulation was modified only after a few years. For example, in Italy, the RDF sector was changed by Decree 205/2010, referring to 30 technical documents (mainly in the range of norms UNI CEN/ TS 15357-15747), which establish all the characteristics, definitions, sampling methods, parameters of interest and analytical methods for the SRF.

SRF is defined as follows: 'SRF is the solid fuel prepared (means processed, homogenized and up-graded to a quality that can be traded amongst producers and users) from non-hazardous waste to be utilized for energy recovery in incineration or co-incineration plants and meeting the classification and specification requirements laid down in CEN/TS 15359'. The classification system for SRFs is based on limit values for three important fuel properties (Table 2). 
Table 1: Technical specifications for RDF and RDF_Q (d.m. = dry matter; as is = wet basis).

\begin{tabular}{|c|c|c|c|c|c|}
\hline \multicolumn{3}{|c|}{ RDF } & \multicolumn{3}{|c|}{ RDF_Q } \\
\hline Charact. & Units & $\begin{array}{l}\text { Limit of } \\
\text { acceptance }\end{array}$ & Charact. & Units & $\begin{array}{l}\text { Limit of } \\
\text { acceptance }\end{array}$ \\
\hline Moisture & $\%$ as is & $\max .25$ & Moisture & $\%$ as is & $\max .18$ \\
\hline LHV & $\mathrm{MJ} / \mathrm{kg}$ as is & $\min .15$ & LHV & MJ/ kg d.m. & $\min .20$ \\
\hline Ash content & $\%$ d.m. & $\max .20$ & Ash content & $\%$ d.m. & $\max .15$ \\
\hline As & mg/ kg d.m. & $\max .9$ & As & mg/ kg d.m. & $\max .5$ \\
\hline $\mathrm{Cd}$ & - & - & $\mathrm{Cd}$ & $\mathrm{mg} / \mathrm{kg}$ d.m. & $\max .3$ \\
\hline $\mathrm{Hg}$ & - & - & $\mathrm{Hg}$ & mg/ kg d.m. & $\max .1$ \\
\hline $\mathrm{Cd}+\mathrm{Hg}$ & mg/ kg d.m. & $\max .7$ & $\mathrm{Cd}+\mathrm{Hg}$ & - & - \\
\hline Total Cl & $\%$ as is & $\max .0 .9$ & Total Cl & $\%$ d.m. & $\max .0 .7$ \\
\hline $\mathrm{Cr}$ & mg/ kg d.m. & $\max .100$ & $\mathrm{Cr}$ & $\mathrm{mg} / \mathrm{kg}$ d.m. & $\max .70$ \\
\hline Soluble $\mathrm{Cu}$ & mg/ kg d.m. & $\max .300$ & Soluble $\mathrm{Cu}$ & $\mathrm{mg} / \mathrm{kg}$ d.m. & $\max .50$ \\
\hline $\mathrm{Mn}$ & mg / kg d.m. & $\max .400$ & $\mathrm{Mn}$ & $\mathrm{mg} / \mathrm{kg}$ d.m. & $\max .200$ \\
\hline $\mathrm{Ni}$ & mg/ kg d.m. & $\max .40$ & $\mathrm{Ni}$ & mg/ kg d.m. & $\max .30$ \\
\hline Volatile $\mathrm{Pb}$ & mg/ kg d.m. & $\max .200$ & Volatile $\mathrm{Pb}$ & mg/ kg d.m. & $\max .100$ \\
\hline S & $\%$ as is & $\max .0 .6$ & $\mathrm{~S}$ & $\%$ d.m. & $\max .0 .3$ \\
\hline Glass content & $\%$ d.m. & $*$ & Glass content & $\%$ d.m. & $*$ \\
\hline $\mathrm{Fe}$ & $\%$ d.m. & $*$ & $\mathrm{Fe}$ & $\%$ d.m. & $*$ \\
\hline Fluorine & $\%$ d.m. & $*$ & Fluorine & $\%$ d.m. & $*$ \\
\hline $\mathrm{Al}$ & $\%$ d.m. & $*$ & $\mathrm{Al}$ & $\%$ d.m. & $*$ \\
\hline $\mathrm{Sn}$ & $\%$ d.m. & $*$ & $\mathrm{Sn}$ & $\%$ d.m. & $*$ \\
\hline $\mathrm{Zn}$ & $\%$ d.m. & $*$ & $\mathrm{Zn}$ & $\%$ d.m. & $*$ \\
\hline Exterior aspect & - & $*$ & Exterior aspect & - & $*$ \\
\hline Dimensions & $\mathrm{mm}$ & $*$ & Dimensions & $\mathrm{mm}$ & $*$ \\
\hline Ash softening & ${ }^{\circ} \mathrm{C}$ & $*$ & Ash softening & ${ }^{\circ} \mathrm{C}$ & $*$ \\
\hline
\end{tabular}

*For this parameter, a limit is not set.

*For this parameter, a limit is not set.

Each property is divided into five classes with limit values. The SRF is assigned a class number from 1 to 5 for each property. A combination of class numbers makes up the class code. The parameters are of equal importance, and thus no single class number determines the code. Table 3 summarizes the SRF specifications required in various plants.

An important parameter for SRF characterization is the potential rate of microbial self-heating. This rate can be determined by the real dynamic respiration index (RDRI $=$ average value of the respiration indexes, referring to total dry solids, TDS, representing $24 \mathrm{~h}$ with the highest aerobic micro-activity). Until 2010, when the most recent EU norms CEN/TR 15590 were enforced, this parameter was only required for the stabilized organic fraction (UNI/TS 11184, 2006) and not for fuels. Now, this RDRI parameter has become a key parameter for SRF. Table 4 shows the levels of potential microbial self-heating of an SRF. 
Table 2: Technical specifications for SRF (ar = as received; $d=$ dry) [20].

\begin{tabular}{|c|c|c|c|c|c|c|c|}
\hline \multirow{2}{*}{$\begin{array}{l}\text { Classification } \\
\text { property }\end{array}$} & \multirow{2}{*}{$\begin{array}{l}\text { Statistical } \\
\text { measure }\end{array}$} & \multirow[b]{2}{*}{ Unit } & \multicolumn{5}{|c|}{ Classes } \\
\hline & & & 1 & 2 & 3 & 4 & 5 \\
\hline Net calorific value & Mean & $\mathrm{MJ} / \mathrm{kg}(\mathrm{ar})$ & $\geq 25$ & $\geq 20$ & $\geq 15$ & $\geq 10$ & $\geq 3$ \\
\hline Chlorine $(\mathrm{Cl})$ & Mean & $\%(\mathrm{~d})$ & $\leq 0.2$ & $\leq 0.6$ & $\leq 1.0$ & $\leq 1.5$ & $\leq 3$ \\
\hline Mercury (Hg) & Median 80th & $\mathrm{mg} / \mathrm{MJ}$ (ar) & $\leq 0.02$ & $\leq 0.03$ & $\leq 0.08$ & $\leq 0.15$ & $\leq 0.5$ \\
\hline & percentile & & $\leq 0.04$ & $\leq 0.06$ & $\leq 0.16$ & $\leq 0.30$ & $\leq 1.0$ \\
\hline
\end{tabular}

Table 3: Overview of specifications (end-users).

\begin{tabular}{|c|c|c|c|c|c|c|c|}
\hline & \multirow[b]{2}{*}{ Unit } & \multirow[b]{2}{*}{ Cement } & \multicolumn{2}{|c|}{ Hard coal } & \multirow{2}{*}{$\frac{\text { Brown coal }}{\text { DBB }}$} & \multirow[b]{2}{*}{ FBC } & \multirow[b]{2}{*}{$\mathrm{FBC}(\mathrm{AC})$} \\
\hline & & & DBB & WBB & & & \\
\hline LHV & $\mathrm{MJ} / \mathrm{kg}$ & $5-22$ & $13.5-18$ & $17-22$ & $13.5-18$ & $13.5-18$ & $13.5-18$ \\
\hline $\mathrm{Cl}$ & $\%$ ar & $0.5-3$ & $0.5-1.0$ & $1.0-2.0$ & $0.4-0.7$ & $0.4-1.4$ & $0.4-1.4$ \\
\hline $\mathrm{Hg}$ & $\mathrm{mg} / \mathrm{MJar}$ & $0.08-0.33$ & 0.065 & 0.034 & 0.085 & 0.028 & 0.26 \\
\hline $\mathrm{Cd}$ & $\mathrm{mg} / \mathrm{MJar}$ & 6.90 & 1.21 & 0.25 & 0.42 & 0.63 & 85 \\
\hline
\end{tabular}

AC, active coal used absorbant; ar, as received; DBB, dry bottom boiler pulverized coal, dry ash; WBB, wet bottom boiler pulverized coal, molten slag; FBC, fluidized bed combustion.

Table 4: RDRI values.

\begin{tabular}{ll}
\hline $\mathrm{RDRI}\left[\mathrm{mg} \mathrm{O}_{2} \mathrm{~kg}^{-1} \mathrm{TS} \mathrm{h}^{-1}\right]$ & Potential microbial self-heating \\
\hline$<500$ & Very low \\
$500-1000$ & Low \\
$1000-2000$ & Moderately high \\
$2000-3000$ & High \\
$>3000$ & Very high \\
\hline
\end{tabular}

The solution for producing SRF can influence the RDRI, because of the presence of putrescible materials in the treated waste. In Germany (BMU, 2001) and Austria (BKA, 2004) the respiration activity and the self-heating test as stability parameters for biologically treated waste have been common for a few years [21].

SRF can also be produced from source-separated dry combustible fractions, which cannot be used for recycling, such as cardboard drink containers or PE/PET bottles contaminated by PVC, packaging waste or rejects from manufacturing, scrap tyres, discarded biomass (e.g. straw, untreated wood waste, dried sewage sludge), waste textiles and residues from car dismantling. The limit of $50 \%$ of special waste makes putrescible waste in the streams of RMSW to be classified as SRF less critical.

There are various types of SRF that can be produced; such as fluff, brick, briquette, pellet, logtype and bale. They all have one general characteristic: the more complex the treatment involved in generating it, the more energy consuming the approach. 


\section{THE ROLE OF BIO-DRYING AND SELECTIVE COLLECTION SCENARIOS}

The production of waste derived from human activity has increased because of population increases, and especially due to economic development which has transformed consumption patterns. The systems of waste collection are also changing, leading to an overall complex scenario where balanced interactions are compulsory [18]. In many cases, on the other hand, decision makers do not adopt a coordinated strategy.

In the last few years, the efficiency of SC has increased in some European countries, leading to the possibility to obtain a RMSW with interesting energy content and a low level of contamination (fewer heavy metals, etc.). One question raised in the sector concerns the potential classification of RMSW directly as SRF, in compliance with the requirements of CEN/TS 15359 [20].

The aim of this paper was thus to analyse the interactions of bio-drying with SC together with the possibility of obtaining SRF characteristics with or without bio-drying. We use the term SC to refer to the source separation of typical MSW fractions (road sweeping and bulky waste are not taken into account at this level). The main MSW streams are assumed to be collected by curbside organization, street containers or eco-centres.

Scenario 1 refers to an EU region with an overall MSW SC of 10\% [22, 23]. This scenario is a representative of a region, without a significant $\mathrm{SC}$, which could relate to the present situation not only for new EU countries but also in some not optimized EU regions. Scenario 2 has a high SC, equal to $65 \%$ [24] and is a representative of a region with a significant SC (in this case, the data regard the current situation in a northern area of Italy).

In the first case study, SC consists of street containers, whereas in the second scenario, curbside collection is adopted. Table 5 presents data regarding waste characteristics and SC streams for both case studies. Data for the first case-study come from the results of a national study in Romania [23] concerning rural and urban areas, based on 30 characterizations of RMSW, just after Romania had joined the EU. Data for the second case-study come from the results of a multi-year characterization of RMSW in Trentino, Italy [25]. RMSW (and SC) were characterized in great detail over the last decade, with reference to different seasons, towns and valleys in the northeast of Italy.

For a better understanding of the long-term dynamics of SC efficiency, Fig. 1 reports the dynamics of SC over the last 20 years for a real case study. The increase in MSW generation from 1995 to 2011 was $16 \%$ [25]. In the first case study, SC shows a delay of 13 years.

Table 5: MSW and RMSW composition, SC streams and LHVs.

\begin{tabular}{llclllll}
\hline & \multicolumn{3}{c}{ Case 1(\%) } & & \multicolumn{3}{c}{ Case 2 (\%) } \\
\cline { 2 - 3 } Waste fraction & MSW & SC stream & RMSW & & MSW & SC stream & RMSW \\
\hline Food waste & 42.72 & 0.00 & 47.45 & & 26.74 & 22.50 & 12.13 \\
Paper and cardboard & 9.15 & 3.26 & 6.55 & & 25.10 & 16.60 & 24.36 \\
Plastics & 8.14 & 1.57 & 7.29 & & 13.21 & 10.64 & 7.35 \\
Glass & 5.09 & 2.46 & 2.92 & & 3.34 & 3.00 & 0.96 \\
Metals & 8.14 & 2.38 & 6.39 & & 10.21 & 5.50 & 13.50 \\
Wood & 3.05 & 0.30 & 3.06 & & 4.57 & 3.70 & 2.47 \\
Textiles & 5.41 & 0.00 & 6.01 & & 7.98 & 0.36 & 21.82 \\
Inert & 7.12 & 0.00 & 7.91 & & 4.67 & 2.78 & 5.41 \\
Mixed materials & 11.19 & 0.00 & 12.43 & & 4.19 & 0 & 12.01 \\
LHV (kJ/kg) & 7245 & - & 6564 & & 9404 & - & 12,684 \\
\hline
\end{tabular}


For the bio-drying weight loss, the following expression can be used [9]:

$$
\mathrm{BML}=0.63 \cdot \mathrm{FW} \%
$$

where BML is the bio-drying mass loss and $\mathrm{FW} \%$ is the food waste percentage.

To assess the LHV obtainable after bio-drying post-treatments, the remaining amount of glass, metals and inert in the bio-dried material was assumed as being totally removable. This approximation is acceptable because the efficacy of recyclable material separation from a bio-dried material is very high. The energy loss from the initial LHV during bio-drying was assumed to be negligible [26]: the initial energy is all concentrated in a lower mass. Table 5 also presents the energy contents of MSW and RMSW; LHVs are assessed according to literature data [9, 26]. Data from Table 5 enable the level of source separation for each stream for both the case studies to be assessed (Table 6). These rates have significant consequences on the RMSW characteristics: in fact, the percentage of FW in the first case is around 50\%, whereas in the second case it is only approximately $12 \%$.

Taking into account the SC trend, which increases at around 3\% every year (as reported in Fig. 1), the SC efficiency for both case studies is presented in Table 5 and the increment in the MSW

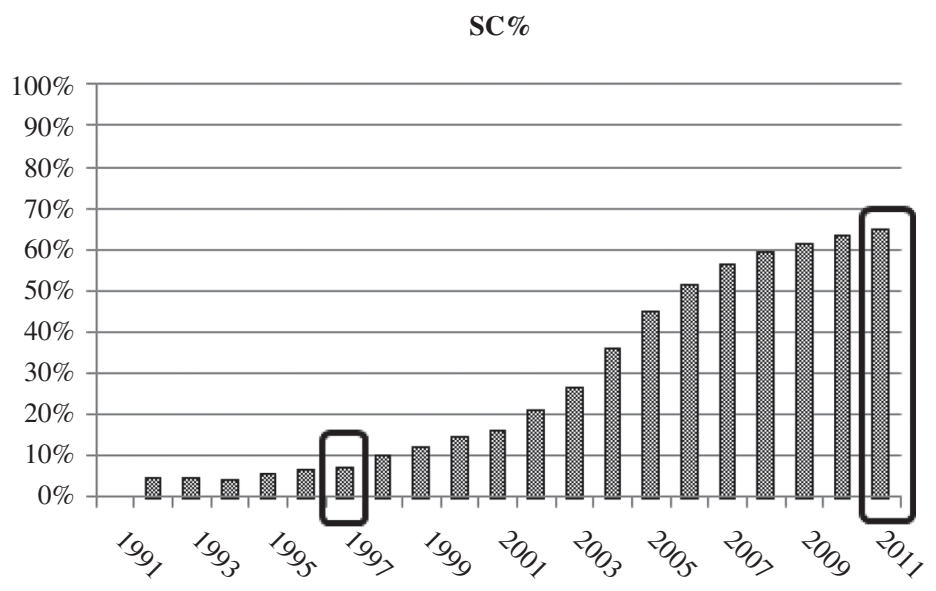

Figure 1: SC efficiency in a real case region.

Table 6: SC rates.

\begin{tabular}{lcc}
\hline Waste fraction & Case 1 $(\%)$ & Case 2 $(\%)$ \\
\hline Food waste & 0.00 & 84.1 \\
Paper and cardboard & 35.6 & 66.1 \\
Plastics & 19.3 & 80.6 \\
Glass & 48.4 & 89.9 \\
Metals & 29.2 & 53.8 \\
Wood & 9.8 & 81.1 \\
Textiles & 0.00 & 4.52 \\
Inert & 0.00 & 59.59 \\
Mixed materials & 0.00 & 0.00 \\
\hline
\end{tabular}


generation from 1995 to 2011. It is clear that for the second case, the targets for 2013 and also for 2020 have already been reached.

In the first case study, a reorganization of the SC is essential with a yearly incremental rate that is significantly different from the second case. Indeed, while in the first case study the yearly SC increase rate was the same as in the second case, in 2013 the SC efficiency would be only $17 \%$ and $23 \%$ in 2015 (new EU members could be allowed an additional 2 years to comply with EU requests regarding biodegradable material landfilling).

The bio-drying process could thus be adopted for a transient period to comply with EU requirements, not only for the biodegradable material targets but also for the energy generation form waste.

Table 7 reports the LHVs for the materials before and after bio-drying and post-treatment. Mass loss during bio-drying and the potential of extractable recyclable materials for both cases are also presented.

It is clear that bio-drying enables the initial LHV to be increased with a higher performance when the FW percentage is higher. In the second case, the role of bio-drying seems more interesting as a preparative step before the post-treatment of incombustible material separation. In fact, the LHV increase from bio-dried material to SRF is clearer than the one from RMSW to bio-dried material.

Figure 2 presents the relative composition of recyclable materials suitable for post-separation after bio-drying. Real-scale experiences [7] have demonstrated that the quality of glass and metals extracted is suitable for the market; on the other hand, inert could give some problems when valorizing it. However, its separation is important to increase the LHV of the SRF; thus, it should be always implemented.

Table 7: Characteristics of pre- and post-processed waste.

\begin{tabular}{lccccc}
\hline & $\begin{array}{c}\mathrm{LHV}_{\mathrm{RMSW}} \\
(\mathrm{kJ} / \mathrm{kg})\end{array}$ & $\begin{array}{c}\mathrm{LHV}_{\text {bio-dried mat. }} \\
(\mathrm{kJ} / \mathrm{kg})\end{array}$ & $\mathrm{LHV}_{\mathrm{SRF}}(\mathrm{kJ} / \mathrm{kg})$ & Mass loss $(\%)$ & $\begin{array}{c}\text { Recyclable } \\
\text { materials (\%) }\end{array}$ \\
\hline Case 1 & 6564 & 9363 & 12,626 & 29.9 & 18.1 \\
Case 2 & 12,684 & 13,734 & 16,130 & 7.6 & 13.7 \\
\hline
\end{tabular}

\section{Recyclable materials from post-treatment}

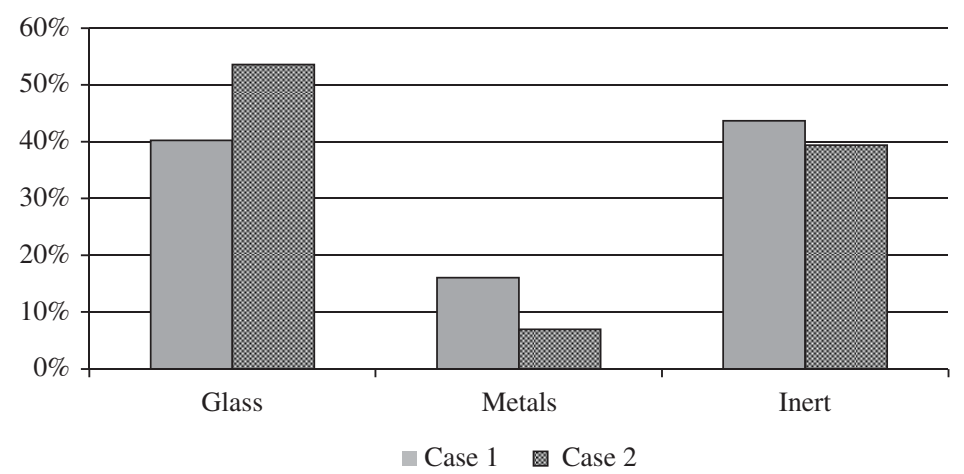

Figure 2: Percentage of recyclable materials. 
Table 8: Product classification.

\begin{tabular}{|c|c|c|c|c|}
\hline & \multicolumn{2}{|r|}{ Case 1} & \multicolumn{2}{|r|}{ Case 2} \\
\hline & Class & Co-combustion & Class & Co-combustion \\
\hline RMSW & $5,1,1$ & Cement factory & $4,1,1$ & Incineration, cement factory, coal \\
\hline $\mathrm{LHV}_{\text {bio-dried mat }}$ & $5,1,1$ & & $3,1,1$ & thermal power plant \\
\hline $\mathrm{LHV}_{\mathrm{SRF}}$ & $4,1,1$ & & $3,1,1$ & \\
\hline
\end{tabular}

The percentage of recyclable materials in Table 7 refers to RMSW, thus highlighting their different roles in the two cases. In the first case, $18 \%$ must be applied to an RMSW equal to $90 \%$ of MSW, resulting in a higher recycling stream (16.2\%) than SC (10\%). On the other hand, in the second case $14 \%$ must be applied to a stream of RMSW equal to $35 \%$ of the generated MSW, resulting in a considerably lower recyclable stream (4\%) than the SC (65\%).

Taking into account only the LHV of RMSW, bio-dried material and SRF, and also the new EU directives and technical norms for the SRF, Table 8 presents the class for RMSW, bio-dried material and SRF for both case studies together with recommendations for their co-combustion [7]. It should be highlighted that according to the old regulations, only the final product obtained in the second case could be classified as RDF [7].

For the calculation of chlorine and mercury content in the RMSW in both case studies, literature data were used [27]. The chlorine and mercury contents are: 0.0040 and 0.0038 for $\mathrm{Cl}$ in $\%$ (DM) and 0.0078 and 0.0040 for $\mathrm{Hg}$ in $\mathrm{mg} / \mathrm{MJ}$, respectively. Taking into account these values, which are lower than those required by the SRF norms, for bio-dried material and SRF, the contents of $\mathrm{Cl}$ and $\mathrm{Hg}$ are expected to be very low and the products will be classified as class 1 .

It is important to point out that the use of bio-drying in the second case study, despite the LHV of RMSW being adequately high for an efficient direct combustion, leads to the generation of a class 3 SRF. This interesting result will be more appreciated when a real market for SRF exists in the EU.

When analysing the coexistence of SC and bio-drying, the most important aspects to consider are as follows:

- Role of post-treatment after bio-drying vs. SC: The evolution of SC significantly reduces the amount of recyclable materials that can be extracted after bio-drying; however, equipment costs are similar as the post-treatment lines take into account the tonnes of RWMS to be treated. The values above reported clearly indicate that the cost of SRF generation must be carefully verified before constructing a new plant. For existing plants, some consequences on the costs of treatment must be expected.

- Bio-drying performance in a transient SC scenario: The annual decrease in FW content in the RMSW causes a variation in the characteristics of the SRF that can be generated. Particular attention must be paid for long-term contracts for SRF selling, if specific characteristics are required. The decrease in mass through bio-drying can be very low in the case of $\mathrm{SC}$, which diverts most of the FW stream.

- Maximizing SC refuse and bio-drying compatibility: SC of light combustible packaging waste (cardboard, plastics) generally has a high percentage of non-recyclable materials with high LHV. This stream grows where SC increases. This stream can be enhanced by adding it to the biodried material to generate a better SRF. This addition could be upstream or downstream of the biological stage. 
- SC variability and environmental impact of bio-drying: SC diverts waste from the feed of the bio-drying plant. In terms of planning, the plant capacity could be reduced and this would also lessen the local impact. In the case of existing plants, a decrease in FW percentage in the input leads to a lower air flow rate and thus a lower stream of pollutants emitted into the atmosphere. Some pollutants are related to the amount of VS consumed in the process: less FW means less VS consumption, and thus less impact. Ammonia emissions are, for instance, related to the nitrogen content in FW and to its consumption [7].

- SC and bio-drying plant capacity (existing plants): If the area of RMSW collection is fixed, a decrease in RMSW caused by an increase in SC can be problematical for a bio-drying plant manager. Indeed, if the amount of local treatable waste decreases without the possibility of adding external waste, the running costs of the plant becomes critical. A potential solution could be the addition of special waste. The advantages of the generable SRF on the LHV could be interesting.

- SC and bio-drying plant design difficulties: The process air lines and the volume of the biocontainers are designed in relation to a specific RMSW. If FW in RMSW decreases, the amount of air for the process decreases; thus, the air treatment line becomes over-dimensioned, with clear diseconomies. The SC scenario must be clear in the long term when a bio-drying plant is planned and designed.

Finally, it should be highlighted that RMSW cannot be directly classified as SRF if sufficiently low RDRI values are required to make a specific treatment necessary.

\section{CONCLUSIONS}

In this paper, some coexistence issues in terms of bio-drying and $\mathrm{SC}$ have been analysed referring to two different SC scenarios. The aim was to help fill the gap in knowledge of MBTs in the sector.

A rapid SC increase can cause significant problems for bio-drying plants when the collection scenario is rigid, i.e. no MSW can be imported and treated from external areas).

Additionally, the role of this biological process is debatable when the effect of SC is to significantly lower the FW percentage in RMSW.

Finally, the cost of post-treatment after bio-drying can be affected by the limited amount of recyclable materials left from the source separation activities.

As demonstrated by the presented calculations, one important aspect concerns the role of MSW SC. Its optimization can change the characteristics of RMSW; however, it is generally essential to treat the waste so that it can become SRF because of the adoption of a respirometric index which prevents overly simplified schemes of SRF generation.

\section{REFERENCES}

[1] EC-Directorate-General Environment, Directorate A-Sustainable Development and Policy Support, Working document, Biological treatment of biowaste, 2nd draft, Brussels, 12 February, 2001.

[2] Donovan, S.M., Bateson, T., Gronow, J.R. \& Voulvoulis, N., Characterization of compostlike outputs from mechanical biological treatment of municipal solid waste. Journal of the Air and Waste Management Association, 60(6), pp. 694-701, 2010. doi: http://dx.doi. org/10.3155/1047-3289.60.6.694

[3] Montejo, C., Tonini, D., Márquez, M.D.C. \& Fruergaard Astrup, T., Mechanical-biological treatment: performance and potentials. An LCA of $8 \mathrm{MBT}$ plants including waste characterization. Journal of Environmental Management, 128, pp. 661-673, 2013. doi: http://dx.doi.org/10.1016/j. jenvman.2013.05.063 
[4] Ionescu, G., Rada, E.C., Ragazzi, M., Marculescu, C., Badea, A. \& Apostol, T., Integrated municipal solid waste scenario model using advanced pretreatment and waste to energy processes. Energy Conservation and Management, 76, pp. 1083-1092, 2013. doi: http://dx.doi. org/10.1016/j.enconman.2013.08.049

[5] Siddiqui, A.A., Powrie, W. \& Richards D.J., Impact of pretreatment on the landfill behaviour of MBT waste. WIT Transactions on Ecology and the Environment, 173, pp. 627-638, 2013. doi: http://dx.doi.org/10.2495/sdp130521

[6] Rada, E.C., Ragazzi, M. \& Apostol, T., Municipal solid waste bio-drying viability in different countries. Proc. of mechanical biological waste treatment and material recovery facilities, Gottingen Cullivier Verlag: Hanover, pp. 565-570, 2009.

[7] Ragazzi, M. \& Rada, E.C., RDF/SRF evolution and MSW bio-drying, Waste Management and the Environment IV, eds., V. Popov, H. Itoch \& C.A. Brebbia, Wit Press: Southampton, 163, pp. 199-208, 2012. doi: http://dx.doi.org/10.2495/wm120191

[8] Velis, C.A., Longhurst, P.J., Drew, G.H., Smith, R. \& Pollard, S.J.T., Biodrying for mechanicalbiological treatment of wastes: a review of process science and engineering. Bioresource Technology, 100(11), pp. 2747-2761, 2009. doi: http://dx.doi.org/10.1016/j.biortech.2008.12.026

[9] Rada, E.C., Ragazzi, M. \& Badea, A., MSW bio-drying: design criteria from a 10 years research. Scientific Bulletin, series D, 74(3), pp. 209-216, 2012.

[10] Velis, C.A. \& Cooper, J., Are solid recovered fuels resource-efficient? Waste Management and Research, 31(2), pp. 113-114, 2013. doi: http://dx.doi.org/10.1177/0734242x13476385

[11] Velis, C.A., Longhurst, P.J., Drew, G.H., Smith, R. \& Pollard, S.J.T., Production and quality assurance of solid recovered fuels using mechanical-biological treatment (MBT) of waste: a comprehensive assessment. Critical Reviews in Environmental Science and Technology, 40(12), pp. 979-1105, 2010. doi: http://dx.doi.org/10.1080/10643380802586980

[12] Velis, C., Wagland, S., Longhurst, P., Pollard, S., Robson, B. Sinfield, K. \& Wise, S., Solid recovered fuel: influence of waste stream composition and processing on chlorine content and fuel quality. Environmental Science and Technology, 46(3), pp. 1923-1931, 2012. doi: http:// dx.doi.org/10.1021/es2035653

[13] Choi, Y.S., Han, S., Choi, H.S. \& Kim, S.J., Characterization of Korean solid recovered fuels (SRFs): an analysis and comparison of SRFs. Waste Management and Research, 30(4), pp. 442-449, 2012. doi: http://dx.doi.org/10.1177/0734242x12441239

[14] Skutan, S. \& Brunner, P.H., Metals in RDF and other high calorific value fractions from mechanical treatment of MSW: analysis and sampling errors. Waste Management and Research, 30(7), pp. 645-655, 2012. doi: http://dx.doi.org/10.1177/0734242x12442740

[15] ERFO-European Recovered Fuel Organisation, SRF: achieving environmental and energyrelated goals market - Workshop Quo Vadis on 22 June 2006 in Larnaca Cyprus, 2006.

[16] Glorius, T., Production and Use of Solid Recovered Fuels - Developments and Prospects, Berliner Abfallwirtschafts- und Energiekonferenz Berlin 30. - 31.01.2012,

[17] Rada, E.C. \& Andreottola, G. RDF/SRF: which perspective for its future in the EU. Waste Management, 32(6), pp. 1059-1060, 2012. doi: http://dx.doi.org/10.1016/j.wasman.2012.02.017

[18] Consonni, S., Giugliano, M., Massarutto, A., Ragazzi, M. \& Saccani, C., Material and energy recovery in integrated waste management systems: project overview and main results. Waste Management, 31(9-10), pp. 2057-2065, 2011. doi: http://dx.doi.org/10.1016/j.wasman.2011.04.016

[19] Ragazzi, M. \& Rada, E.C., Effects of recent strategies of selective collection on the design of municipal solid waste treatment plants in Italy. WIT Transactions on Ecology and the Environment, eds. M. Zamorano, C.A. Brebbia, A.G. Kungalos, V. Popov \& H. Itoh, Wit Press: Southampton, 109, pp. 613-620, 2008. 
[20] CEN/TC 15359:2006 - Solid recovered fuels - Specifications and classes. doi: http://dx.doi. org $/ 10.3403 / 30141009$

[21] Binner, E., Böhm, K. \& Lechner, P., Large scale study on measurement of respiration activity (AT4) by Sapromat and OxiTop. Waste Management, 32(10), pp. 1752-1759, 2012. doi: http:// dx.doi.org/10.1016/j.wasman.2012.05.024

[22] Raicu, S., Costescu, D., Roşca, E. \& Popa, M., Optimal planning of selective waste collection. WIT Transactions on Ecology and the Environment, 150, pp. 785-794, 2011. doi: http://dx.doi. org/10.2495/sdp110651

[23] ANPM (National Agency of Environment Protection), 2009. Report regarding MSW collection, valorification and recycling in 2009 (Romania), http://www.anpm.ro (accessed in 2012).

[24] Ionescu, G. \& Rada, E.C., Material and energy recovery in a municipal solid waste system: practical applicability. International Journal of Environment and Resource, 1(1), pp. 26-30, 2012.

[25] PAT - Autonomous Province of Trento, Internal data-base, (2012).

[26] Rada, E.C., Franzinelli, A., Taiss, M., Ragazzi, M., Panaitescu, V. \& Apostol, T., Lower heating value dynamics during municipal solid waste bio-drying. Environmental Technology, 28(4), pp. 463-469, 2007. doi: http://dx.doi.org/10.1080/09593332808618807

[27] Rotter, V.S., Kost, T., Winkler, J. \& Bilitewski, B. Material flow analysis of RDF-production processes. Waste Management, 24(10), pp. 1005-1021, 2004. doi: http://dx.doi.org/10.1016/j. wasman.2004.07.015 